\title{
Participation of women in HIV clinical trials: the IPEC-FIOCRUZ experience
}

This article was published in the following Dove Press journal:

HIVIAIDS - Research and Palliative Care

30 June 2011

Number of times this article has been viewed

\author{
Jordan E Lake' \\ Ruth K Friedman ${ }^{2}$ \\ Cynthia B Cunha ${ }^{2}$ \\ Sandra W Cardoso ${ }^{2}$ \\ Valdilea G Veloso² \\ Judith S Currier' \\ Beatriz Grinsztejn ${ }^{2}$ \\ 'Division of Infectious Diseases, \\ University of California at Los \\ Angeles, Los Angeles, CA, USA; \\ ${ }^{2}$ Fundação Oswaldo Cruz - Instituto \\ de Pesquisa Clínica Evandro Chagas/ \\ IPEC, Rio de Janeiro, State of Rio de \\ Janeiro, Brazil
}

Correspondence: Jordan E Lake UCLA Division of Infectious Diseases, 99II W. Pico Boulevard, Suite 980 Los Angeles, CA 90035, USA

Tel + I 310557 I89|

Fax + I 310557 I899

Email jlake@mednet.ucla.edu
Background: Fifty percent of people living with human immunodeficiency virus (HIV) or acquired immunodeficiency syndrome (AIDS) worldwide are female. In Brazil, for example, 240,000 women are infected with HIV, rates of infection in women have increased over the last two decades, and addressing HIV prevention and treatment for women at risk for, or living with, HIV/AIDS remains a challenge. To better address the needs of women living with HIV in Brazil, the Instituto de Pesquisa Clínica Evandro Chagas - Fundação Oswaldo Cruz (IPEC-FIOCRUZ) HIV Women's Cohort was established in 1996 to study the natural history of women seeking HIV care. This analysis describes the characteristics of women in the cohort who participated in HIV clinical trials between 1999 and 2008.

Methods: A total of 736 Women's Cohort participants were in active follow-up and 665 participants from the Women's Cohort were included in univariable and multivariable analyses to determine socioeconomic and sociodemographic factors associated with women's participation in HIV clinical trials at our site.

Results: Of the complete cohort, 23\% participated in a clinical trial between January 1999 and July 2008. Odds of participation decreased for women who were younger than 35 years old, currently employed, had an HIV-positive sexual partner, and/or who reported a lifetime history of illicit drug use. Alternatively, the odds of participation increased for women who had more than 8 years of formal education, were living independently, and/or were married or cohabitating. Conclusion: The rate of participation in HIV clinical trials by women in the IPEC-FIOCRUZ Cohort was similar to other published cohorts, but identification of local risk factors and barriers to participation remains important. Our analysis offers a novel description of the factors associated with participation in HIV clinical trials among women in care at IPEC-FIOCRUZ in Rio de Janeiro, Brazil.

Keywords: AIDS, Brazil, South America, clinical trial participation

\section{Background}

For more than a decade, women have comprised half of all people living with human immunodeficiency virus (HIV) or acquired immunodeficiency syndrome (AIDS) - an estimated 15.9 million women worldwide in 2009. One-third of all HIV-infected persons in Central and South America live in Brazil, 240,000 of whom are women. ${ }^{1}$ Brazil's proactive national response to providing prevention and treatment services has kept overall infection rates stable and has significantly decreased mortality. ${ }^{2}$ Rates of infection among women, however, have increased, with a shift in male-to-female infection rates from $15: 1$ in 1986 to $1.5: 1$ in 2002. Since 2002, the male-to-female infection rate has stabilized. ${ }^{3,4}$ Among persons aged 13-19 years, a ratio reversal in the number of AIDS cases has occurred, with 0.8:1 male-to-female AIDS cases reported. ${ }^{4}$ 
With 29\% of women aged 15-24 reporting onset of sexual activity before the age of $15,{ }^{1}$ addressing HIV prevention and treatment for women at risk for, or living with, HIV/AIDS in Brazil remains a challenge. Despite this, prior to 2007 , monies were not allocated for HIV/AIDS programs targeting women (other than for the prevention of mother-to-child transmission) in Brazil. ${ }^{4}$

In recent years, increased awareness of the need for representative inclusion of women in HIV clinical trials has emerged, and this has been a priority of the UNAIDS (Joint United Nations Programme on HIV/AIDS) Global Coalition on Women and AIDS since its inception in 2004. This need stems both from increasing numbers of women living with HIV worldwide, and differences between men and women in terms of: clinical outcomes, including safety and efficacy; pharmacokinetic profiles of antiretroviral therapies (ARTs); socioeconomic factors; and barriers to care and prevention.

Not unexpectedly, factors associated with women's participation in clinical trials seem to vary by geographic region and community, with little data published on the participation of women in Central and South America. This is problematic, as the successful development of future HIV programs and policies targeting women is dependent upon addressing the needs of women within individual communities. This analysis was designed to assess factors contributing to HIV clinical trial participation among women in the Instituto de Pesquisa Clínica Evandro Chagas - Fundação Oswaldo Cruz (IPECFIOCRUZ) Women's Cohort.

\section{Materials and methods Study population}

Since 1986, investigators at the IPEC-FIOCRUZ, a large referral center for HIV research and care in Rio de Janeiro, Brazil, have provided care to HIV-positive men and women. In 1996, the IPEC-FIOCRUZ Women's Cohort was established to study the natural history of women seeking care at their site. Criteria for inclusion in the cohort include documentation of HIV-positive status and willingness and ability to provide informed consent. Cohort procedures have been described in previously published analyses. ${ }^{5-7}$ A total of 764 women were enrolled in the cohort between May 1996 and July 2008. Of the 764 women enrolled, 28 women died or were lost to follow-up prior to the opening of the first HIV clinical trial at IPECFIOCRUZ in January 1999, and never had the opportunity to participate in clinical trials. A total of 736 women were in active follow-up between January 1999, when the first HIV clinical trial opened, and July 2008. Since that time, 34 HIV prevention and therapy trials have been open to enrollment for women.
This analysis was performed to describe the characteristics of women in the cohort who participated in HIV clinical trials between 1999 and 2008, as well as to assess whether these women were representative of the IPEC-FIOCRUZ Women's Cohort as a whole, or whether certain populations of women should be targeted to equalize representation in our trials.

\section{Selection of subjects}

IPEC-FIOCRUZ HIV Women's Cohort participants who had a documented visit after January 1, 1999 were assessed for this study. All cohort participants that did not participate in a clinical trial contributed to this analysis. For women that participated in a clinical trial, we excluded those without cohort baseline data within 1 year of enrollment in a trial. This exclusion criterion was created to represent sociodemographic and socioeconomic factors near the time of trial enrollment as accurately as possible. Baseline demographics at the time of clinical trial entry could not be included in this analysis because different trials collected different demographic information. The combined total number of women who did not participate in a clinical trial and those that participated and had cohort baseline data within 1 year of enrollment in a clinical trial were included in the analysis of factors associated with participation in clinical trials. A flow chart describing subject selection is provided in Figure 1.

All procedures were approved by the IPEC-FIOCRUZ institutional review board, and all participants were willing and able to provide informed consent.

\section{Covariates}

Covariates selected for univariable analysis were: age; race/ ethinicity (self-reported; White/non-White); years of formal education; employment status (yes/no); independent living status (yes/no; this variable refers to subject's ability to provide her own independent housing versus living in the home of her family or friends; it does not refer to cohabitation or roommate status); married or living as married (yes/no); presence of an emotional or financial support from a network (yes/no); number of living children; children living with HIV/ AIDS (yes/no); substance use (alcohol and illicit drugs) (yes/ no); history of sexual abuse (yes/no); history of domestic violence (yes/no); sexual partner's HIV status (yes/no); and partner's substance abuse or dependence (yes/no).

\section{Statistical analysis}

The primary objective was to identify factors associated with the participation of women in clinical trials at the FIOCRUZ site. The primary outcome was the dichotomous participation 


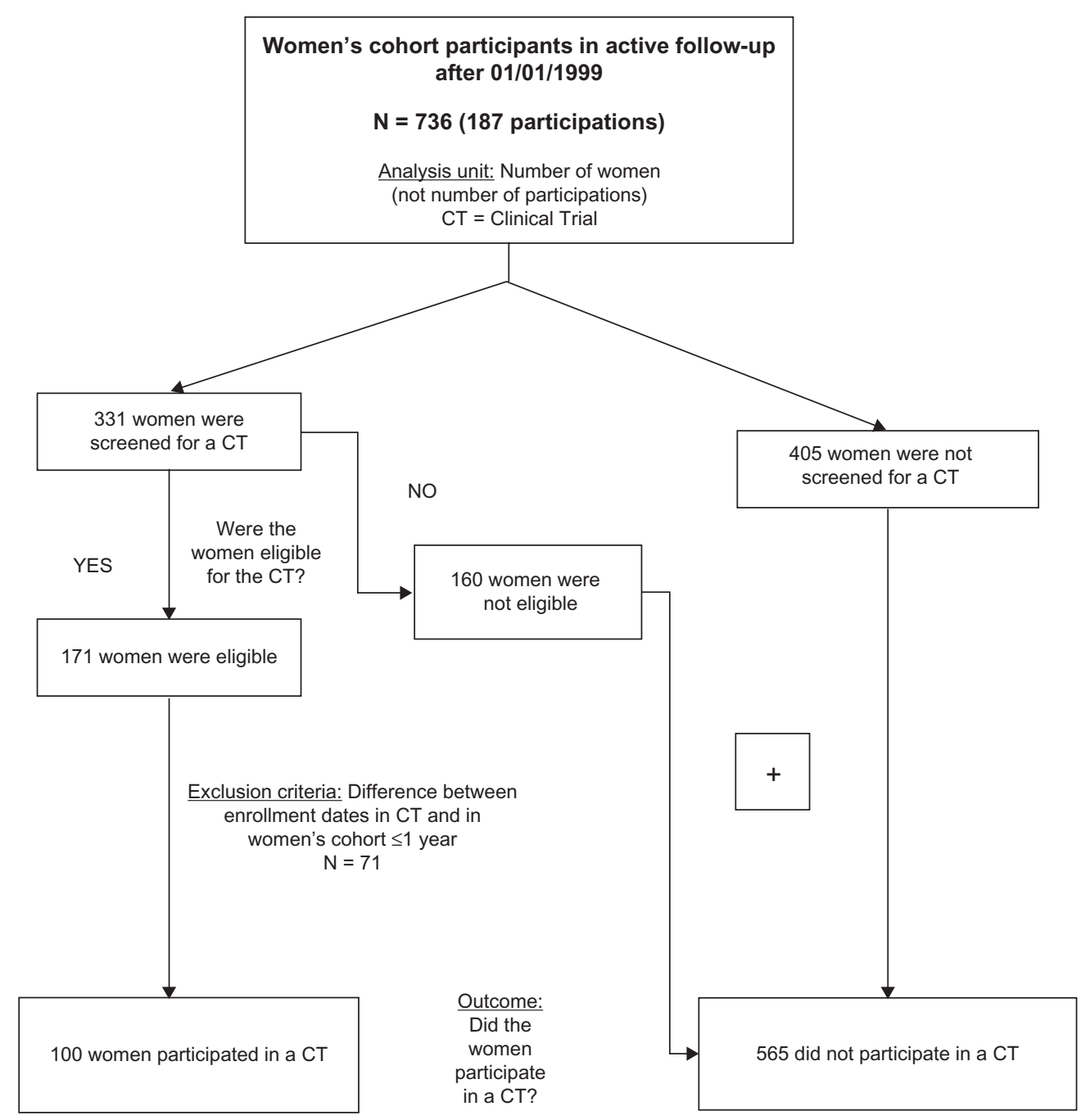

Figure I IPEC-FIOCRUZ (Instituto de Pesquisa Clínica Evandro Chagas - Fundação Oswaldo Cruz) Women’s Cohort: screening and participation in clinical trials. Rio de Janeiro, Brazil, 1999-2008.

of women in clinical trials. Women who did not participate served as the internal control group.

Covariate selection was performed via a multistep process using the strategy proposed by Bursac. ${ }^{8}$ First, univariable analysis was performed using the chi-square test for categorical variables, and the analysis of variance method for continuous variables. The threshold for inclusion in the initial multivariable logistic regression model was set at $P<0.25$. Only those women with complete datasets were included in the multivariable model.

Collinearity was assessed for among covariates that were statistically significant in the univariable analysis; tolerance values below 0.40 were considered as having high multicollinearity (Allison ${ }^{9}$ ). Therefore, variables included in the multivariable model were both significant in the univariable analysis and had a tolerance value greater than or equal to 0.40 .
The Wald statistic and likelihood ratio test were then performed to test the appropriateness of removing each variable from the multivariable model. Confounders were defined as variables that, when removed, resulted in a $>20 \%$ change in the beta coefficient of any other variable. Variables were removed pass-by-pass, starting with the highest $P$ value. A $P \leq 0.10$ to enter criterion was set as the threshold to retain the variable in the model (first stage). Variables considered confounders were retained in the model. In the second stage, variables with $P>0.25$ in the univariable analysis were entered into the model. Criteria to retain variables in the final model were the same as in the first stage of multivariable analysis. Model fitness was verified through calculation of the Akaike information criterion and the degree of statistical dispersion. Overdispersion was not present.

Residual analysis was performed using the deviance, Pearson residuals, and Cook's distances, as well as leverage 
graphics. Univariable analysis was conducted using SPSS Statistics (IBM Corporation, Somers, NY) software 13.0, and R 2.10.0 software was utilized in the multivariable analyses.

\section{Results}

\section{Cohort characteristics}

Of women who were in active cohort follow-up between January 1, 1999 and October 7, 2008 ( $\mathrm{n}=736), 331(45.0 \%)$ were approached for participation in at least one clinical trial; $51.7 \%$ of those approached $(23.2 \%$ of the complete cohort, or $\mathrm{n}=171 / 736)$ were eligible and enrolled in at least one clinical trial. A total of $7.0 \%(n=12 / 171)$ enrolled in more than one clinical trial, with a total of 187 subject participations over the 9 -year period (Figure 1). A total of 85/171 women participated in ART-naïve clinical trials, 72/171 participated in trials for ART-experienced subjects, and 16/171 participated in trials where ART status requirements were not defined. A list of trials offered at our site between January 1999 and October 2008 is provided in Table 1.

\section{Participant characteristics}

A total of 665 of the 736 cohort participants were included in the analysis; 100 women participated in a clinical trial and had baseline cohort data obtained within 1 year of enrollment into a trial; 71 women were excluded from the analysis because they participated in a clinical trial more than 1 year after cohort enrollment. Characteristics of subjects included in the analyses are summarized in Table 2. The mean age was 35 years, and most women were non-White, unemployed, had 8 years or less of formal education, reported not having any kind of emotional or financial support, were not cohabitating with a partner, lived independently, and had at least one living child. Nearly two-thirds of women reported having a sexual partner of negative or unknown HIV status. Fewer than $50 \%$ had a partner who was an illicit drug user or had self-reported alcohol consumption or illicit drug use. A history of sexual abuse and/or domestic violence was common.

One hundred women $(15.0 \%)$ participated in at least one clinical trial; mean CD4 count and HIV-1 viral load were 225 cells $/ \mathrm{mm}^{3}$ (standard deviation [SD] 171 cells $/ \mathrm{mm}^{3}$, median 206 cells $/ \mathrm{mm}^{3}$ ) and 236,504 copies/mL (SD 445,713 copies/mL, median 77,319 copies/mL), respectively.

\section{Univariable analysis}

A comparison of categorical variables between women who did and did not participate in clinical trials is also presented
Table I Number of women enrolled in each clinical trial conducted at IPEC-FIOCRUZ (1999-2008)

\begin{tabular}{|c|c|c|c|}
\hline & $\begin{array}{l}\text { Clinical trial } \\
\text { number }\end{array}$ & $\begin{array}{l}\text { Year of } \\
\text { enrollment }\end{array}$ & $\begin{array}{l}\text { Number } \\
\text { of women }\end{array}$ \\
\hline \multirow[t]{11}{*}{ ART-naïve } & TMC 278 & 2005 & 5 \\
\hline & $2 \mathrm{NN}$ & 2001 & 4 \\
\hline & A5I75 & 2005 & 35 \\
\hline & A522I & 2007 & 2 \\
\hline & \multirow[t]{2}{*}{ Al $424-138$} & 2006 & 2 \\
\hline & & 2007 & 1 \\
\hline & BI I 882.33 & 2004 & 2 \\
\hline & CAN 30021 & 2001 & 6 \\
\hline & CAN 30024 & 2001 & 3 \\
\hline & EPV 200I & 2000 & 6 \\
\hline & HPTN052 & 2005 & 19 \\
\hline ART- & A 431-1006 & 2003 & 9 \\
\hline \multirow[t]{21}{*}{ experienced } & A $431-1022$ & 2005 & 1 \\
\hline & Al 424-008 & 2000 & 7 \\
\hline & Al 424-044 & 2001 & 4 \\
\hline & Al 424-045 & 2002 & 3 \\
\hline & Al 424-067 & 2004 & 5 \\
\hline & BI I I82-48 & 2003 & I \\
\hline & CROWN & 2000 & 8 \\
\hline & M06-802 & 2007 & 3 \\
\hline & M98-888 & 2000 & 2 \\
\hline & MK-005 & 2005 & 5 \\
\hline & MK-0I9 & 2006 & I \\
\hline & PRO 317 & 2001 & 6 \\
\hline & \multirow[t]{2}{*}{ TMCII4-C2I5 } & 2004 & 3 \\
\hline & & 2005 & 4 \\
\hline & TMCII4-C229 & 2008 & 5 \\
\hline & TMCI25-C206 & 2006 & 6 \\
\hline & \multirow[t]{2}{*}{$\mathrm{TMCl} 25-\mathrm{C} 217$} & 2005 & 2 \\
\hline & & 2008 & 1 \\
\hline & TMCI25-C227 & 2005 & I \\
\hline & TMC2I4-C2I5 & 2005 & 1 \\
\hline & VICTOR E-3 & 2006 & 7 \\
\hline No ART & FUJISAWA & 2002 & 10 \\
\hline requirement & MLI8743 & 2006 & 6 \\
\hline
\end{tabular}

Abbreviations: ART, antiretroviral therapy; IPEC-FIOCRUZ, Instituto de Pesquisa Clínica Evandro Chagas - Fundação Oswaldo Cruz.

in Table 2. Women who participated in clinical trials were more likely to be $36-45$ years old, have greater than 8 years of formal education, be unemployed, and live independently, but less likely to be married or cohabitating, have a sexual partner that was known to be HIV-positive or actively using substances, or have a personal history of illicit drug use (all $P<0.05)$. A history of sexual abuse $(P<0.10)$ and alcohol consumption $(P<0.25)$ were believed to be confounding issues, and were also entered into the multivariable models.

\section{Multivariable logistic regression analysis}

The final multivariable logistic regression model depicts independent predictors of participation in clinical trials by 
Table 2 Selected baseline characteristics of women according to participation in clinical trials

\begin{tabular}{|c|c|c|c|}
\hline \multirow[t]{2}{*}{ Variable } & \multicolumn{3}{|c|}{ Participated in a clinical trial } \\
\hline & $\mathrm{No}^{\mathrm{a}}$ n (\%) & Yes $^{\mathrm{a}}$ n (\%) & Total $^{\mathrm{a}}$ \\
\hline Total number & 565 & 100 & 665 \\
\hline \multicolumn{4}{|l|}{$A g e^{b}$} \\
\hline$\leq 35$ years & $294(55.1)$ & $33(33.7)$ & $327(51.7)$ \\
\hline $36-45$ years & $161(30.1)$ & $48(49.0)$ & $209(33.1)$ \\
\hline$\geq 46$ years & $79(14.8)$ & $17(17.3)$ & $96(15.2)$ \\
\hline \multicolumn{4}{|l|}{ Skin color } \\
\hline White & $237(44.4)$ & $44(44.9)$ & $28 I(44.5)$ \\
\hline Non-White & $297(55.6)$ & $54(55.1)$ & $35 I(55.5)$ \\
\hline \multicolumn{4}{|l|}{ Education ${ }^{\mathrm{b}}$} \\
\hline$>8$ years & $215(40.6)$ & $5 I(53.1)$ & $266(42.5)$ \\
\hline$\leq 8$ years & $315(59.4)$ & $45(46.9)$ & $360(57.5)$ \\
\hline \multicolumn{4}{|c|}{ Employment status ${ }^{\mathrm{b}}$} \\
\hline Employed & $256(47.9)$ & $34(35, I)$ & $290(46.0)$ \\
\hline Not employed & $278(52.1)$ & $63(64.9)$ & $34 I(54.0)$ \\
\hline \multicolumn{4}{|c|}{ Has emotional or financial support? } \\
\hline Yes & $320(60.2)$ & $64(65.3)$ & $384(61.0)$ \\
\hline No & $212(39.8)$ & $34(34.7)$ & $246(39.0)$ \\
\hline \multicolumn{4}{|c|}{ Lives independently ${ }^{\mathrm{b}}$} \\
\hline Yes & $342(65.4)$ & $76(77.6)$ & $418(67.3)$ \\
\hline No & $181(34.6)$ & $22(22.4)$ & $203(32.7)$ \\
\hline \multicolumn{4}{|c|}{ Married or living as married ${ }^{b}$} \\
\hline Yes & $206(38.6)$ & $49(50.0)$ & $255(40.3)$ \\
\hline No & $328(6 I .4)$ & $49(50.0)$ & $377(59.7)$ \\
\hline \multicolumn{4}{|c|}{ Has an HIV-positive partner ${ }^{\mathrm{b}}$} \\
\hline Yes & $214(40.5)$ & $25(25.8)$ & $239(38.2)$ \\
\hline No & $315(59.5)$ & $72(74.2)$ & $387(61.8)$ \\
\hline \multicolumn{4}{|c|}{ Has a partner who uses drugs ${ }^{\mathrm{b}}$} \\
\hline Yes & $77(14.4)$ & $5(5.1)$ & $82(13.0)$ \\
\hline No & $457(85.6)$ & $93(94.9)$ & $550(87.0)$ \\
\hline \multicolumn{4}{|c|}{ Number of living children } \\
\hline None & $92(17.7)$ & $17(17,3)$ & $109(17.6)$ \\
\hline $\mathrm{I}-2$ & $298(57.2)$ & $61(62.2)$ & $359(58.0)$ \\
\hline$>3$ & $|3|(25.1)$ & $20(20.4)$ & $|5|(24.4)$ \\
\hline \multicolumn{4}{|c|}{ Children living with HIV/AIDS } \\
\hline Yes & $48(9.8)$ & $7(7.3)$ & $55(9.4)$ \\
\hline No & $386(78.8)$ & $74(77.1)$ & $460(78.5)$ \\
\hline Childless & $56(11.4)$ & $15(15.6)$ & $71(12.1)$ \\
\hline \multicolumn{4}{|c|}{ History of sexual abuse ${ }^{c}$} \\
\hline Yes & $109(20.6)$ & $12(12.4)$ & $121(19.3)$ \\
\hline No & $420(79.4)$ & $85(87.6)$ & $505(80.7)$ \\
\hline \multicolumn{4}{|c|}{ History of domestic violence } \\
\hline Yes & $184(35.0)$ & $32(33.3)$ & $216(34.8)$ \\
\hline No & $34 \mid(65.0)$ & $64(66.7)$ & $405(65.2)$ \\
\hline \multicolumn{4}{|c|}{ Any alcohol consumption ${ }^{d}$} \\
\hline Yes & $214(40.1)$ & $32(32.7)$ & $246(38.9)$ \\
\hline No & $320(59.9)$ & $66(67.3)$ & $386(61.1)$ \\
\hline \multicolumn{4}{|c|}{ Lifetime illicit drug use $\mathrm{e}^{\mathrm{b}}$} \\
\hline Yes & $152(28.5)$ & $17(17.3)$ & $169(26.7)$ \\
\hline No & $382(7 \mid .5)$ & 81 (82.7) & $463(73.3)$ \\
\hline
\end{tabular}

Notes: a Total values are not the same for all variables as a consequence of missing values; ${ }^{\mathrm{P} P}$ value $<0.05$; ${ }^{\mathrm{C} P}$ value $<0.10$; ${ }^{\mathrm{d}} \mathrm{P}$ value $<0.25$.

Abbreviations: AIDS, acquired immunodeficiency syndrome; HIV, human immunodeficiency virus. the 585 women in our cohort with complete data (Table 3). Women who participated in clinical trials were more likely to: have greater than 8 years of formal education (adjusted odds ratio $[\mathrm{AOR}]=2.28 ; P=0.001)$, be married or cohabitating (AOR $=1.96, P=0.007)$, and be living independently $(\mathrm{AOR}=1.69, P=0.059)$. Women were less likely to have participated in a clinical trial if they: were less than 35 years of age $(\mathrm{AOR}=0.29, P<0.001)$, were currently employed (AOR $=0.50, P=0.006$ ), had an HIV-positive sexual partner $(\mathrm{AOR}=0.43, P=0.002)$, or reported illicit drug use $(\mathrm{AOR}=0.52, P=0.035)$.

\section{Discussion}

In 1993, the US National Institutes of Health mandated the participation of women in clinical trials, ${ }^{10}$ and the US Food and Drug Administration repealed its exclusion of women of childbearing age in trials, ${ }^{11,12}$ setting a global precedent. Since then, with the help of the UNAIDS Global Coalition on Women and AIDS, awareness of the need for equitable inclusion of women in prevention and therapeutics trials has increased worldwide. Overall, 23\% of the IPEC-FIOCRUZ Women's Cohort participated in a

Table 3 Multiple logistic regression for women's participation in clinical trials, IPEC-FIOCRUZ, Brazil ${ }^{a}$

\begin{tabular}{|c|c|c|}
\hline Variable & $\begin{array}{l}\text { Adjusted odds } \\
\text { ratio }(95 \% \mathrm{Cl})\end{array}$ & $P$-value \\
\hline \multicolumn{3}{|l|}{ Age } \\
\hline$\leq 35$ years & $0.29(0.17-0.50)$ & $<0.001$ \\
\hline $36-45$ years & 1.00 & \\
\hline$\geq 46$ years & $0.78(0.39-\mid .5 I)$ & 0.475 \\
\hline \multicolumn{3}{|l|}{ Education } \\
\hline$>8$ years & $2.28(1.40-3.76)$ & 0.001 \\
\hline$\leq 8$ years & 1.00 & \\
\hline \multicolumn{3}{|c|}{ Employment status } \\
\hline Employed & $0.50(0.30-0.81)$ & 0.006 \\
\hline Unemployed & 1.00 & \\
\hline \multicolumn{3}{|c|}{ Lives independently } \\
\hline Yes & $1.69(1.00-2.98)$ & 0.059 \\
\hline No & 1.00 & \\
\hline \multicolumn{3}{|c|}{ Married or living as married } \\
\hline Yes & $1.96(1.20-3.22)$ & 0.007 \\
\hline No & 1.00 & \\
\hline \multicolumn{3}{|c|}{ Has an HIV-positive partner? } \\
\hline Yes & $0.43(0.25-0.73)$ & 0.002 \\
\hline No & 1.00 & \\
\hline \multicolumn{3}{|c|}{ Lifetime illicit drug use } \\
\hline Yes & $0.52(0.28-0.93)$ & 0.035 \\
\hline No & 1.00 & \\
\hline
\end{tabular}

Note: al I.7\% (78/665) of women who had a missing value in at least one variable selected from univariable analysis was excluded.

Abbreviations: $\mathrm{Cl}$, confidence interval; $\mathrm{HIV}$, human immunodeficiency virus; IPECFIOCRUZ, Instituto de Pesquisa Clínica Evandro Chagas - Fundação Oswaldo Cruz. 
clinical trial between January 1999 and July 2008. While there is little published data on the participation of women in HIV clinical trials in other parts of Central and South America, these values are similar to rates of participation seen between 1993 and 1998 in the Canada Women's HIV Study. ${ }^{13}$

In our cohort, the odds of participation in an HIV clinical trial decreased for women who were younger than 35 years old, were currently employed, had an HIV-positive sexual partner, and who reported a lifetime history of illicit drug use. However, the odds of participation in an HIV clinical trial increased for women who had more than 8 years of formal education, were living independently, and were married or cohabitating.

Decreased rates of participation by women younger than 35 years of age may reflect the exclusion by many trials of women who are pregnant, desire to become pregnant, or are nursing. Since data on safety in pregnancy often lags behind efficacy data for novel therapeutic agents, this obstacle is difficult to overcome for therapeutics trials. However, attempts can be made to increase the number of women under 35 in HIV prevention trials where the intervention is not of potential harm to a fetus (ie, behavioral interventions), and in other trials when contraception is readily available for women who choose not to become pregnant.

Years of formal education has been shown to be predictive of trial participation for both men and women, ${ }^{13,14}$ which may reflect literacy requirements, access to care, and/or an overall sense of empowerment in directing one's health care (although these factors have not explicitly been explored). Feelings of empowerment have previously been documented as a reason for participation in trials, particularly in communities where HIV infection remains highly stigmatized $^{13}$ and/or access to care is poor. Since 1996, universal access to care and combination ART has been available to all HIV-infected Brazilians, eliminating access to care as a primary motivation for trial participation. Access to experimental medications, however, remains a potential motivating factor, especially for those drugs being developed for salvage therapy.

Employment status was inversely correlated with trial participation in our cohort. Because Brazil prohibits monetary compensation for participation in clinical trials, financial incentive did not confound our analysis. Rather, unemployment may correlate with an increased availability to comply with study visits and procedures. Similarly, having an HIV-positive or substance-abusing partner may reflect a woman's role as caregiver and/or earner for her family, which, like employment, could decrease her ability to participate in a trial and comply with study schedules and procedures.

Unmarried status has been shown to be a risk factor for the acquisition of HIV and other sexually transmitted infections in women in Brazil and elsewhere, ${ }^{16-18}$ a finding that may arise from a number of factors, including: increased number of sexual partners, decreased ability to negotiate safer sex, and decreased health awareness. Lack of participation in clinical trials may reflect a similar lack of self-health promotion, or other factors such as the lack of a social support network. Our study, however, was not designed to elucidate reasons for nonparticipation.

Other factors associated with clinical trial participation have also been studied. History or current use of injection drugs is consistently a predictor of trial nonparticipation, ${ }^{13,19-21}$ as it was in our cohort. In the USA and Canada, Caucasian ethnicity has been shown to be a predictor of participation in trials. ${ }^{13,14,19,20,22}$ Participants in our cohort were more likely to be non-White by self-report, a finding we believe reflects the high prevalence of multiethnic persons at our referral center. In keeping with previously published data, the need for conscious recruitment of ethnic minorities in all communities remains critical.

\section{Limitations}

This analysis is not without limitations. First, a complete medical and social history is taken at the time of enrollment in our cohort, and data on select items is updated every 6 months thereafter. Updated information for all covariates, however, is not re-obtained at the time of trial enrollment. In an effort to improve the accuracy of our data and its relevance to a participant's decision-making process, we excluded women from the analysis who did not have a Women's Cohort baseline visit within 1 year of entering a trial. Second, subjects were not specifically asked why they decided to participate in a clinical trial or not. We also do not have data on the proportion of men from our clinical site that agree to participate or be screened for clinical trials as a reference category. Finally, this analysis was not stratified by study type, and factors predicting trial participation are likely to vary between therapeutic, biomedical prevention, and behavioral intervention trials. The potential barriers to care indentified in this analysis are, however, instrumental in shaping future recruitment 
efforts and designing trials to better serve the needs of our patient population.

The 565 women who did not participate in clinical trials included both subjects who were screened but not eligible for a clinical trial $(n=160)$, and subjects who were not screened for or offered participation in a clinical trial $(n=405)$. Women are routinely prescreened for participation at our site, and the refusal rate of those approached to participate is very low. Therefore, most women who were screened but found to be ineligible were believed to be eligible by prescreening but developed an exclusion criterion between prescreening and screening. The decision to screen in our cohort is based upon entry criteria for currently available studies, and should not be subject to physician bias in the same way that failure to approach a woman for participation could be.

Women that were not screened for a clinical trial may not have been asked to participate for a variety of reasons. First, women would not have been asked to participate if the prescreening process determined them to be ineligible. This is often the case for women that are well controlled on their current ART, as many of our studies target treatment-naïve patients or those in need of salvage therapy. Second, women were asked to participate based on the type of trial being conducted. Therefore, women on ART could not have been asked to participate, for example, if only treatment-naïve studies were available at a given time. Third, women may have been eligible for but not asked to participate if the number of female or total enrollment slots was limited. Lastly, some women may not have been approached to participate for reasons not captured above (physician preference, etc).

\section{Conclusion and future directions}

Our analysis offers a novel description of the factors associated with the participation of women in HIV clinical trials at IPEC-FIOCRUZ in Rio de Janeiro, Brazil. Because the participation of women in HIV clinical trials varies greatly with geography and sociodemographic makeup, ongoing local assessment of recruitment and retention barriers is important for ensuring future success in enrolling adequate numbers of women in HIV clinical trials. This is particularly important for communities in Central and South America and other communities whose needs have not yet been well described. By ensuring the adequate representation of women in clinical trials, we hope to achieve the goal of optimizing care and minimizing toxicities and comorbidities for women living with HIV.

\section{Acknowledgments}

We would like to thank the Women's Cohort participants for their time and cooperation, as well as the IPEC-FIOCRUZ staff that helped to make this study possible.

\section{Disclosure}

The authors report no conflicts of interest in this work. This work was not supported by specific grant funding.

\section{References}

1. UNAIDS. Global Report: UNAIDS Report on the Global Aids Epidemic 2010. UNAIDS; 2010.

2. UNAIDS. Epidemiological Fact Sheet on HIV/AIDS. UNAIDS; 2008.

3. Villela W, Kraiczyk J. Integrated Plan to Combat the Feminization of the AIDS Epidemic and Other STDs: an Analysis Two Years After Launching. Unifesp; 2007.

4. Health Surveillance Secretariat, STD, AIDS and Viral Hepatitis Department, Brazilian Ministry of Health. Targets and Commitments Made by Member-states at the United Nations General Assembly Special Session on HIV/AIDS. Brazilian Ministry of Health; 2010.

5. Grinsztejn B, Bastos FI, Veloso VG, et al. Assessing sexually transmitted infections in a cohort of women living with HIV/AIDS, in Rio de Janeiro, Brazil. Int J STD AIDS. 2006;17(7):473-478.

6. Grinsztejn B, Veloso VG, Levi JE, et al. Factors associated with increased prevalence of human papillomavirus infection in a cohort of HIV-infected Brazilian women. Int J Infect Dis. 2009;13(1): 72-80.

7. Luz P Vl, Friedman R, et al. Cervical cytological abnormalities and factors associated with high-grade squamous intra-epithelial lesions among HIV-infected women from Rio de Janeiro, Brazil. Int J STD AIDS. In press; 2011.

8. Bursac Z, Gauss CH, Williams DK, Hosmer DW. Purposeful selection of variables in logistic regression. Source Code Biol Med. 2008;3:17.

9. Allison PD. Logistic Regression Using the SAS System: theory and application. Cay, NC: SAS Institute Inc; 1999.

10. National Institutes of Health (NIH). NIH guidelines on the inclusion of women and minorities as subjects in clinical research. NIH Guide for Grants and Contracts. 1994;23(11).

11. Merkatz RB, Temple R, Sobel S, Feiden K, Kessler DA, and the Working Group on Women in Clinical Trials. Women in clinical trials of new drugs: a change in food and drug administration policy. N Engl J Med. 1993;329(4):292-296.

12. US Food and Drug Administration. Guideline for the study and evaluation of gender differences in the clinical evaluation of drugs; notice. Fed Regist. 1993;58(139):39406-39416. Referenced at: http:// www.hhs.gov/ohrp/humansubjects/guidance/hsdc94-01.htm and http://grants.nih.gov/grants/olaw/p1103-43.pdf. Accessed June 13, 2011.

13. Hankins C, Lapointe N, Walmsley S, and the Canadian Women's HIV Study Group. Participation in clinical trials among women living with HIV in Canada. CMAJ. 1998;159(11):1359-1365.

14. Cotton DJ, Finkelstein DM, He W, Feinberg J. Determinants of accrual of women to a large, multicenter clinical trials program of human immunodeficiency virus infection: the AIDS Clinical Trials Group. J Acquir Immune Defic Syndr. 1993;6(12):1322-1328.

15. Gifford AL, Cunningham WE, Heslin KC, et al. Participation in research and access to experimental treatments by HIV-infected patients. NEngl J Med. 2002;346(18):1373-1382.

16. Diaz T, Chu SY, Sorvillo F, et al. Differences in participation in experimental drug trials among persons with AIDS. J Acq Immun Def Synd. 1995;10(5):562-568. 
17. Stadler JJ, Delany S, Mntambo M. Women's perceptions and experiences of HIV prevention trials in Soweto, South Africa. Soc Sci Med. 2008; 66(1):189-200.

18. Wilkinson D, Abdool Karim SS, Williams B, Gouws E. High HIV incidence and prevalence among young women in rural South Africa: developing a cohort for intervention trials. J Acq Immun Def Syndr. 2000;23(5):405-409.

19. De Lima Soares V, de Mesquita AM, Cavalcante FG, et al. Sexually transmitted infections in a female population in rural north-east Brazil: prevalence, morbidity and risk factors. Trop Med Int Health. 2003; 8(7):595-603.
20. Pechansky F, von Diemen L, Kessler F, Hirakata V, Metzger D, Woody Ge. Preliminary estimates of human immunodeficiency virus prevalence and incidence among cocaine abusers of Porto Alegre, Brazil. J Urban Health. 2003;80(1):115-126.

21. Stone VE, Mauch MY, Steger K, Janas SF, Craven DE. Race, gender, drug use, and participation in AIDS clinical trials: lessons from a municipal hospital cohort. J Gen Intern Med. 1997;12(3): $150-157$.

22. Worthington CA, Gill MJ. Participation in HIV research: the importance of clinic contact factors. AIDS Patient Care STDS. 2008;22(8): 619-625.

\section{Publish your work in this journal}

HIV/AIDS - Research and Palliative Care is an international, peerreviewed open-access journal focusing on advances in research in HIV, its clinical progression and management options including antiviral treatment, palliative care and public healthcare policies to control viral spread. The journal welcomes original research, basic science, clinical \& epidemiological studies, reviews \& evaluations, expert opinion \& commentary, case reports \& extended reports. The manuscript management system is completely online and includes a very quick and fair peer-review system. Visit http://www.dovepress.com/ testimonials.php to read real quotes from published authors.

Submit your manuscript here: http://www.dovepress.com/hivaids---research-and-palliative-care-journal 